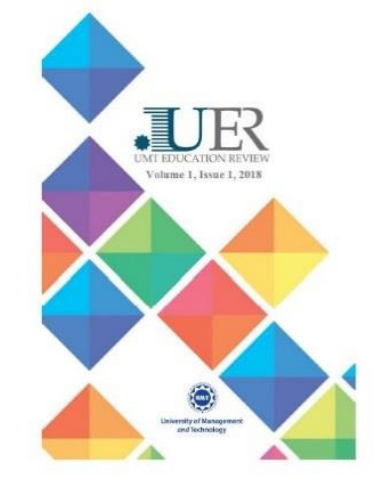

UMT Education Review (UER)

Volume No.1, Issue No. 1, 2018

ISSN: 2616-9738 (Print) 2616-9746 (Online)

Journal DOI: https://doi.org/10.32350/uer

Issue DOI: https://doi.org/10.32350/uer/11

Homepage: https://ssh.umt.edu.pk/uer/home.aspx

Journal QR Code:

\title{
Book Review: $\quad$ Language, Gender and Power: The Politics of Representation and Hegemony in South Asia
}

Author(s): $\quad$ Irfana Omar

Online Published: 2018

Article DOI: $\quad$ https://doi.org/10.32350/uer/11/06

Article QR Code:

To cite this Book Irfana Omar. (2018). Language, Gender and Power: The politics of Review: representation and hegemony in South Asia. UMT Education Review, $1(1), 79-83$.

\section{Crossref}

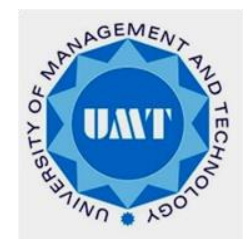

A publication of the

Department of Education

School of Social Sciences and Humanities

University of Management and Technology

Lahore 


\title{
Book Review
}

\section{Book Review}

\section{Language, Gender and Power: The Politics of Representation and Hegemony in South Asia}

\author{
Irfana Omar \\ Assistant Professor, University of Central Punjab
}

"Language, Gender, and Power" by Dr. Shahid Siddiqui is a ten year experience wrapped in 206 pages that unveils the catena among three threads. The book is superb as the writer knows his craft well and combines research and meaningful anecdotes with practical applications. The text is packed with so much critical information related to reform through language that it requires a lot of reflection and internalizing. The author flashes out the idea that language is a powerful tool that carves identities to fit in the gender roles in our society. Dr. Shahid Siddiqui is looking at the phenomenon of gender by opting as an outsider's role for himself. Throughout the book he has remained impartial and I haven't been unable to discern the color of any personal feelings in this scholarly writing.

In six parts, consisting of 20 chapters, Shahid Siddiqui unfolds the string of three variables-language, gender, and power- by accentuating the role of language to construct ideologies which in turn create common-sense assumptions against certain social behaviors. The author corroborates what I believe to be true about the power of language and validates these arguments with research. He asserts that it was not long ago when language was studied in isolation on an 'etherized table' which underestimated its influence on socio-cultural dimensions by tagging $\mathrm{X}$ as a superior language and $\mathrm{Y}$ as an inferior language. It was Saussure who punctuated the fact that use of a language defines its strength in a certain society. The author well-illustrates his point with an example from history regarding the deterioration of Persian language. With the descent of Mughal Empire and preeminence of the British in the subcontinent, Persian which was considered a symbol of status and esteem was replaced by English due to the strong hold and power of the speakers associated with this language. Moreover, proficiency of English language was pronounced on the basis of accuracy in grammar. It was Hymens (1972) who imported the idea of 'communication competence' to intensify the social appropriateness of a language in a certain context.

I accord with author's allusion of Fairclough (2001) who expounded a deeper thought and underlined the 'internal and dialectical relationship' between language and society. Sociological factors like age , social class, social relationship, gender, religion, education, and ethnicity also impact the choice of words and use of language in a given society, but this relationship between society and language was 'unidirectional' which mirrored the passive role of language as merely a tool of communication. Sapir further added an inventive thought that it is not only that society influences language but also language that constructs society; consequently, there was a shift in the role of 
language - from passive to active - and it was no longer considered a neutral entity, rather a highly social, political, and cultural phenomenon.

I punctuate the author's emphasis on Gramsci's notion of hegemony to bring forth the fact that language is directly involved in the process of controlling certain stereotypes dominant in a society which spotlights the political role of language in the dynamics of power. He illustrates his argument by an example that till 1947, USA had a 'War Department' which was changed afterwards into 'Defense Department' and this slight change in the language changed its perception and thus made it more acceptable.

The author highlights the relationship between power and discourse whereby power is associated with control and hegemony. Moreover, the time is gone when coercion was used to exercise power to control people. Now in this post-modern world discursive approach is more useful as 'power is everywhere' and language can be used as a tool for control and hegemony. This shows Shahid Siddiqui's bent towards postmodernism in the $21^{\text {st }}$ century and his futuristic approach in shaping the ideologies, perceptions and norms through language. To strengthen his argument he refers to Gramsci who affirms that hegemony through spontaneous consensus is better than coercive force at political level. The author also quotes Foucault who views power as a process and not as a product. This reflects author's use of critical theory to explore the relationship between language and power. He traces the history of this relationship to show up the resistance against traditional violent power and acceptance of a new perception to view this relationship in this post-modern world whereby he takes language as relational and impermanent which is structured by discourse. I would say it's just the beginning of the discourse which will lead to reconstruction of gender for the benefit of humanity. I do not deny that problem of gender and power does not exist. Personally, I do not $100 \%$ agree with the western concept of gender because by creating a sharp divide between genders we lose an important connection between them-i.e., of humanity.

All of my concerns are humanitarian. So I voice for this cause in an effort to reduce misunderstandings and gaps between the genders. Diversity is the order of nature. Being different is not problematic. The problem is attaching a power phenomenon or inferiority-superiority with it. Mug sciences also teach us about division of labor, so what we need to do is to create respect for all roles. It will eliminate pathetic sense of marginalization and ease down the struggle which substantiates inequality among genders.

I appreciate the broad vision of the author in exploring the depth of minor details of common day language that reflects ideologies of a prominent social group. He strengthens his argument with the term 'manufacturing consent' used by Chomsky to highlight the effect of hegemonic groups to represent the disadvantaged groups and shape these representations into wanted realities through negation of their own identities. 


\section{Book Review}

The relationship of gender and power is well portrayed by the author through allusions of Mac Connell, Beauvoir, and Macaulay in holding the stance that gender of women is fixed through the use of vocabulary and words by the dominant culture of superiors. Being a post-modernist, Dr. Shahid Siddiqui, highlights the role of media and internet to reshape the current image of females who are badly portrayed as irrational, unintelligent, troublesome creatures in jokes, proverbs, sayings and slogans. The author has discussed how females are made silent beings and ignored. This idea is supported by examples from literature where females are found to be suppressed. Proverbs, saying, jokes, and societal expectations are very artistically used to show the politics of representation and hegemony in South Asia. The author has also discussed gender representation in nursery rhymes and fairy tales to further highlight the phenomena. I was convinced with the strong stance of Beauvoir and Standoff to support his argument against media in promoting certain stereotypes and the use of harmful jokes instead of healthy jokes.

The author's deep perception of reality is crystal clear through his wellmaintained chain connections between past, present and future to view society. He details the history of marriages in South Asia whereby the trend of early marriages left the females uneducated with added pressure of handling big joint family system. With the passage of time, these voiceless creatures got opportunity to get themselves educated which turned the tables and soon it became difficult for highly educated females to find a match for themselves. Dr. Shahid well illustrates this constructed reality through the example of matrimonial ads used by internet to spotlight the interrelationship among language, gender, and power. The increased number of these ads show the societal stereotypes and underline the gendered expectations that a society possess; for example, girls are expected to be well mannered and obedient in matrimonial ads where they are observed and commented by in laws for their conduct and behavior; similarly, beauty (goori rangat) is also a stereotype attributed to females only.

Section four of the book witnesses diverse talent of the author who peeps deep into the topic through a different perspective i-e education. Dr. Shahid brings forth the role played by educational institutes to shape gender roles through language. He is right in stating that a close analysis of nursery rhymes open up the stereotyped learning material used from the very beginning of child's education which moulds his/her mind to comprehend the world with a marked difference in male and female expectations. I agree with the writer that female are portrayed as dependent, shy, weak, and less secure as opposed to male in our society. I appreciate true depiction of reality by the author because most of our schools represent more or less the same shades of the picture. Such representations through the use of language affect the expectations of society.

The next section marks the wit of author who underpins the role of media in constructing gender roles. He is true in stating that the power of media shall not be 
neglected in shaping the behavior and attitude of our society. He mentions Anastasia to support his stance that this is the responsibility of media to set norms and standards through spreading information in the society but unfortunately it not only widens the gaps but also destroys the positive images. In South Asia, media shapes the culture with a neglected eye on females who are misrepresented as inferiors, playful, and clowns as oppose to men who are considered as superiors. In most of the ads women are represented in a biased way as an object to be displayed for attraction; in most of the newspapers women are tagged with negative provocative adjectives; in most of the TV dramas and films women are shown as subject to male dominance; in most of the songs women are sketched as feeble and confused. He mentions that India and Sri Lanka also face the same situation to support his argument. Dr. Shahid wants the society to change its handling of gender roles through a positive portrayal of females in language. The vocabulary, symbols and adjectives used for female need a cautious revision to restructure and re-culture the society. To establish control it's no more necessary to keep people physically captivated; control is exercised through manipulating minds and behavior, psychological oppression and psychological wars. I appreciate the broader perspective with which the writer has pondered over the topic and his convincing argumentation with varied allusions which influence the reader to go along with him.

In the final section, Dr. Shahid Siddiqui affirms that if we want to reform a better society, we need to reform the language because our focus shall not be the language used by women rather it shall be the language used for women. There is a need to take out women from these constructed discriminations through a change in the use of terms, words and expressions used for them. The writer has his eye on the current scenario when he states that there have been efforts to reduce this gap through the use of neutral language and avoidance of discriminatory language. I completely agree with Dr. Shahid as his observation goes parallel with my experiences as well. Being an educationist, I have experienced teaching my MBA students to use non-discriminatory language in business writings like chairperson instead of chairman Ms. instead of Mrs. and Miss etc. Dr. Shahid also provides a long list of such words which are refreshed at educational institutes and demands that this revision shall be incorporate din other social institutes as well if we really want to change the image of female in our society. The author unfolds the idea from conservative school of thought which discourages this projection of equality through language and still dominates. The dominant religious group is not ready to attach adjectives like independent, rational and productive with female. This gender discrimination is a highly political phenomenon by the powerful and we need to reduce this gap between powerful and powerless for a better postmodern age.

I have found Dr. Shahid to be in favor of feminism as he wants to take out women from the traditional confined domestic walls to reform society. He looks at this defined role from a different perspective and stresses upon a revised role through 


\section{Book Review}

language. He makes his reader aware of the fact that language can be used both as a tool of control and hegemony and as a support to resistance against hegemony through the revision of discourse. He further inculcates critical thinking in his reader through teaching of language. He wants the present generation to be equipped with linguistic power to bring positive reforms in the society.

I appreciate the convincing style of Dr. Shahid Siddiqui who has assembled invaluable resources to shape his thought by bringing in prominent insights of $20^{\text {th }}$ century thinkers with all their simplicity which makes the reader at ease to carry on until he reaches the last line of the book. So I make my final word in stating that everyone who strives to improve gender roles in the socio-political context through linguistic power, especially those in the most complex and challenging contexts, will benefit immeasurably in exploring this thoughtful and powerful book. 